\title{
ESTUDOS DE CASO COMO ESTRATÉGIA DE ENSINO NA FORMAÇÃO DE PROFESSORES DE FÍSICA
}

\author{
Case studies as a methodological strategy in Physics \\ teachers' preparation
}

\author{
Marília Paixão Linhares ${ }^{1}$ \\ Ernesto Macedo Reis ${ }^{2}$
}

\begin{abstract}
Resumo: O estudo é parte de um projeto de pesquisa que investiga estratégias para a formação de professores de ciência apoiada em um ambiente virtual de aprendizagem. $\mathrm{O}$ artigo descreve a estrutura de uma proposta curricular adotada num curso de licenciatura em Física, baseada na idéia de aprendizagem como construção de conhecimentos e na necessidade de transformar o pensamento espontâneo do professor sobre docência. Analisa parte dos resultados obtidos da aplicação desta proposta em que Estudos de Caso foram adotados como estratégia para a promoção do desenvolvimento profissional docente, orientado por atividades de investigação desenvolvidas em torno de problemas curriculares. A análise das concepções dos futuros professores indica que, a partir da reflexão sobre problemas da prática docente, os licenciandos se apropriam dos conhecimentos teóricos disponíveis e modificam suas concepções iniciais sobre conteúdos didáticos, metodologia e ambiente de trabalho.
\end{abstract}

Palavras-chave: Atividades de investigação. Ambiente virtual de aprendizagem. Estudos de caso.

\begin{abstract}
The work is part of a research project that investigates strategies for the formation of science teachers supported by a virtual learning environment. This paper describes a curricular proposal adopted in a physics teacher preparation course, based on knowledge as a construction and on the teacher's spontaneous thought transformation. Cases had been adopted as strategy for the promotion of the teaching of professional development, guided by investigation activities about curricular problems. Future teacher conceptions analyzed indicate that the available theoretical knowledge was appropriate for the students and its initial conceptions about didactic contents, methodology and work environment were modified.
\end{abstract}

Keywords: Investigation activities. Virtual learning environment. Case studies.

\footnotetext{
${ }^{1}$ Física. Doutora em Ciências Exatas. Docente, Programa de Pós-Graduação em Ciências Naturais, Centro de Ciências e Tecnologias, Universidade Estadual do Norte Fluminense Darcy Ribeiro (UENF). Campos dos Goytacazes, RJ. <paixaoli@uenf.br>

${ }^{2}$ Físico. Doutor em Ciências Naturais. Docente, Centro Federal de Educação Tecnológica de Campos (CEFET/ Campos). Rio de Janeiro, RJ. <ereis@cefetcampos.br>
}

\footnotetext{
${ }^{1}$ Av. Alberto Lamego, 2000

Campos dos Goytacazes, RJ 28.013-600
} 


\section{Introdução}

O processo acelerado de mudanças que vem ocorrendo na sociedade contemporânea indica a necessidade de reorientar os propósitos e as ações de instituições e agentes educacionais. A necessidade de mudança tem se projetado nas escolas e sobre o trabalho dos professores por meio das reformas educacionais. Nos últimos anos, a renovação da escola tem sido um tema presente no dia-a-dia de professores, orientadores, diretores, secretários e ministros da educação. No Brasil, a nova Lei de Diretrizes e Bases da Educação (BRASIL, 1996) organiza e estabelece que a educação escolar deve vincular-se ao mundo do trabalho e da prática social. Define o novo Ensino Médio como etapa conclusiva da educação básica. Outros documentos na forma de diretrizes e parâmetros passaram a regulamentar e orientar as definições legais (MENEZES, 2000).

Colocar em prática as propostas contidas nos Parâmetros Curriculares Nacionais (PCN) (BRASIL, 1998) e sua tradução em práticas escolares concretas, requer o trabalho de incontáveis professores, em suas salas de aula, nas mais diversas realidades, em um processo de construção coletiva (KAWAMURA, 2003). As Diretrizes Curriculares para a Formação de Professores da Educação Básica (BRASIL, 2001) estabelecem competências necessárias: à atuação profissional, referentes ao comprometimento com valores inspiradores da sociedade democrática; à compreensão do papel social da escola; ao domínio dos conteúdos e do conhecimento pedagógico; ao conhecimento de processos de investigação; ao gerenciamento do próprio desenvolvimento profissional.

Neste sentido, é grande o desafio da formação de professores capazes de contribuir com a renovação das escolas e das práticas pedagógicas atuais. O papel da universidade enquanto espaço de formação inicial é central para superar deficiências do ensino tradicional. É indispensável oferecer aos professores um desenvolvimento profissional em que eles assumam uma identidade de aprendiz como um aspecto central no processo de mudança educacional.

Diversas propostas demonstram preocupação com essa temática e algumas se mostram particularmente interessadas com uma formação diferenciada do ensino tradicional, que vigora tanto nas universidades quanto no Ensino Médio. Essas preocupações, em geral, são manifestadas por meio da convicção de que uma formação mais crítica, reflexiva, ética e investigativa possa elevar o patamar da qualidade na formação de professores (MENEZES, 1996; NÓVOA, 1992).

O trabalho de Harres (2005) apresenta uma proposta curricular orientada pelo modelo de formação pautado na evolução do conhecimento profissional do professor ${ }^{3}$. O ponto de partida do processo formativo é considerar o conhecimento didático prévio do futuro professor. Pretende-se que esse conhecimento evolua para um saber profissional prático e complexo e para uma concepção investigativa do trabalho docente (PORLÁN, RIVERO, 1998).

${ }^{3}$ Conhecimento profissional: conjunto de crenças, conhecimentos específicos, rotinas e técnicas integrados de forma complexa, crítica, evolutiva investigativa em sala de aula. 
As disciplinas propostas, que compõem o currículo de um curso de licenciatura, estão estruturadas para promover a integração da relação teoria-prática por intermédio da investigação de problemas práticos profissionais, relevantes para a ação educativa. Os resultados obtidos no final da primeira disciplina, de uma série de quatro, foram satisfatórios. Apesar do pequeno avanço conceitual, justificado pelo trabalho inicial, apontaram um significativo avanço nas atitudes ${ }^{4}$ e habilidades de expressão escrita e oral.

Outro autor sugere que a melhoria da formação de professores requer novos procedimentos que explorem as possibilidades interativas dos meios de comunicação e das redes eletrônicas, associados ao uso dos sistemas tradicionais de materiais escritos e cursos presenciais (KRASILCHIK, 1996). Nesta perspectiva, Rezende e Ostermann (2004) apresentaram um ambiente virtual construtivista de aprendizagem, para a formação continuada de professores de Física e Matemática, planejado para promover a integração de aspectos teóricos e metodológicos à prática de sala de aula, interatividade, e incentivar a colaboração entre participantes, de modo a desenvolver o conhecimento profissional do professor. Propõe o uso do ambiente virtual como ferramenta pedagógica de trabalho semipresencial de cursos de licenciatura.

Esses ambientes construtivistas de aprendizagem enfatizam ferramentas de construção e a possibilidade de interação do estudante com a realidade, permitindo a seleção de informações e o gerenciamento das tarefas de aprendizagem. O modelo favorece a atitude reflexiva e a troca de experiências entre os estudantes (STRUCHINER et al., 1998; JONASSEN, 1996).

A modelagem conceitual mais freqüente em ambientes construtivistas de aprendizagem é a aprendizagem baseada em casos (SAVERY, DUFFY, 1995). Os estudos de caso são questões de interesse dos estudantes e podem estimular a aquisição de conhecimentos e habilidades sem que uma exposição formal prévia da informação seja necessariamente fornecida. Permitem a abordagem de uma temática relacionada a um contexto, seleção de recursos educacionais e avaliação crítica dos resultados alcançados (ARAÚJO, 2005, apud KOMATSU, ZANOLLI, LIMA, 1998).

Considerando as orientações destacadas da problemática sobre a formação de professores, desenvolvemos uma proposta de formação inicial comprometida com o processo contínuo de evolução do conhecimento profissional, orientado por atividades de investigação desenvolvidas em torno de problemas curriculares, organizadas em um ambiente virtual de aprendizagem (REIS, LINHARES, 2006; PAIXÃO LINHARES, MACEDO REIS, 2005 ).

O trabalho analisado neste artigo faz parte do projeto de pesquisa sobre formação do professor de ciências baseada na idéia de aprendizagem como construção de conhecimentos e na necessidade de transformar o pensamento espontâneo do professor sobre ensino. $\mathrm{O}$ objetivo do projeto é favorecer a evolução dos saberes dos professores, geralmente apoiados no ensino por transmissão e na aprendizagem por recepção passiva, para um saber profissio-

\footnotetext{
${ }^{4}$ Avanço nas atitudes dos futuros professores quanto a serem conscientes das próprias idéias e de como elas vão mudando; serem críticos quanto à escolha da futura profissão; se comprometerem com a necessidade de mudança na educação; serem conscientes da permanente evolução profissional e da própria responsabilidade nesse processo.
} 
nal prático e complexo, que integre uma concepção investigativa do trabalho docente. A proposta é guiada por atividades de investigação, focada na aprendizagem baseada em caso, e apoiada por um ambiente de aprendizagem, o Espaço Virtual de Aprendizagem (EVA). Análises preliminares do desenvolvimento e da utilização do EVA já foram apresentadas em trabalhos anteriores (REIS, LINHARES, 2005a, 2005b, 2003).

O presente estudo tem como objetivo apresentar a estrutura curricular da primeira de uma série de três disciplinas, e realizar uma avaliação inicial da implementação da proposta. Nesta pesquisa parte-se do pressuposto de que os futuros professores têm concepções sobre o conhecimento profissional docente, forjadas durante sua formação, que refletem modelos didáticos inadequados. Problematizar situações da prática docente favorece a conscientização dessas idéias e permite superá-las por meio da abordagem das situações envolvidas.

\section{Referencial teórico: formação docente}

Existem concepções diferentes sobre como deve ser a formação de professores para que se possa contribuir com a renovação das escolas e das práticas pedagógicas. Diferentes autores têm contribuído com análises sobre a formação de professores. Destacamos as ênfases das análises de alguns: saberes necessários à prática docente, de Freire (2000); necessidades formativas, de Carvalho e Gil-Pérez (2001); conhecimento profissional do professor, de Pórlan e Rivero (1998); perfil do profissional prático-reflexivo, de Schön (1992). Em comum, estes autores propõem aproximar a prática docente da pesquisa, onde questões de interesse sejam investigadas buscando construir o conhecimento relacionado com a prática educacional.

Freire (2000) defende a ação educativa-crítica fundamentada numa ética pedagógica e numa visão de mundo alicerçadas em criticidade, rigorosidade, pesquisa, humildade, tolerância, bom senso, alegria, curiosidade, esperança, competência e generosidade. Na obra Pedagogia da Autonomia, ensina a ensinar partindo do "ser professor". Reflete sobre saberes necessários à prática docente, relacionando exigências que atendam às seguintes temáticas: não há docência sem discência, ensinar não é transferir conhecimento, ensinar é uma especificidade humana.

O autor sugere práticas e mostra a possibilidade de os educadores estabelecerem novas relações e condições para a prática educativa. O texto explora o tema da formação docente ao lado da reflexão sobre a prática educativo-progressista em favor da autonomia do educando. É enfático na crítica ao ensino bancário que deforma a necessária criatividade de educando e educador, apoiado numa metodologia que enfatiza a transmissão direta de conteúdos do professor ou do livro- texto. O desenvolvimento da autonomia requer do educando experiências estimuladoras de tomadas de decisões, e cabe ao professor progressista proporcionar as situações pedagógicas apropriadas.

Outros autores analisam as tendências e experiências inovadoras na formação de professores de ciências (CARVALHO, GIL-PÉREZ, 2001), e destacam a influência que os professores exercem no processo de implementação dos currículos. Abordam diferentes aspectos da formação referenciados no corpo de conhecimentos construído pela pesquisa didática. A ruptura com visões simplistas sobre ensino de ciências é a primeira necessidade 
formativa analisada e justificada pela pouca familiaridade com as contribuições da pesquisa e inovação didática que os professores demonstram ao comentar o saber docente. Sugerem que é possível superar a problemática adotando uma orientação construtivista na formação de professores, baseada no tratamento de situações abertas, na formação de equipes cooperativas de trabalho, na reflexão coletiva, no debate e no aprofundamento dos temas.

Segundo Carvalho e Gil-Pérez (2001), as idéias, atitudes e comportamentos sobre o ensino, devidos a uma longa formação ambiental durante o período em que foram alunos, podem constituir obstáculos para uma atividade docente inovadora, na medida em que se trata de concepções espontâneas, aceitas acriticamente, como parte de uma docência do senso comum. A proposta de uma formação docente como mudança didática exige a oferta de alternativas para o ensino tradicional. Assim, é necessário estar em contato com estratégias de ensino para uma aprendizagem como pesquisa, coerente com a construção de conhecimentos científicos. É prioridade na formação de professores o trabalho com programas de atividades orientados para o tratamento de situações problemáticas. Um tema de estudo poderia ser desenvolvido seguindo alguns passos determinados: propor situações problemáticas que gerem interesse e proporcionem uma concepção preliminar da tarefa; propor o estudo qualitativo que conduza à formulação de problemas mais precisos e à construção de hipóteses; orientar o tratamento científico dos problemas propostos; colocar a manipulação reiterada dos novos conhecimentos em uma variedade de situações, favorecer atividades de síntese, elaboração de produtos e a concepção de novos problemas.

Em outro estudo, que aborda a progressão do conhecimento profissional docente, Porlán e Rivero (1998) elaboram uma síntese ampla das análises de outros autores sobre modelos de formação, e classificam as tendências existentes tendo as concepções epistemológicas como critério principal. O tradicional privilegia o saber acadêmico em detrimento do conhecimento prático, e faz uso de uma metodologia de ensino que carece de fundamentação teórica, caracterizada pela reprodução mecânica do conhecimento acadêmico. O modelo tecnológico se diferencia do tradicional por reconhecer a dimensão prática da atividade docente, entretanto também supervaloriza o conhecimento teórico. O ensino é uma tecnologia constituída de métodos que os professores devem dominar. O saber fenomenológico é privilegiado no modelo espontaneísta, que considera o aprendizado como um processo que ocorre de maneira espontânea, sem necessidade de um planejamento específico; reconhece apenas o conhecimento prático para a progressão do conhecimento profissional do professor e desconsidera as contribuições teóricas.

Os autores propõem um modelo alternativo aos anteriores definindo o conhecimento profissional desejável, caracterizado por um saber acadêmico elaborado, princípios e crenças autônomas e rotinas de ação diversificadas, em contraste com o saber acadêmico enciclopédico, princípio e crenças estereotipados, rotinas e guias de ação mecanizados. Nesta proposta, a formação é baseada no desenvolvimento progressivo das idéias dos professores e a progressão do conhecimento profissional é guiada por atividades de investigação que este desenvolve em torno dos problemas curriculares, que constituem o ponto de encontro entre os conteúdos formativos e as estratégias de formação. Essa proposta pretende melhorar os sistemas de idéias preexistentes, buscando torná-los mais adequados, coerentes e complexos a partir da expressão das concepções dos professores e da consideração de diferentes perspectivas. O último estágio da formação almejada corresponde a um modelo de ensino constru- 
tivista, segundo o qual o perfil profissional é coerente com a idéia do professor investigador que participa de projetos de experimentação curricular e da progressão do conhecimento profissional.

Outro autor que aborda a formação profissional docente é Schön (1992). A questão central na sua obra é a busca por uma epistemologia da prática que tenha, como base, a reflexão inerente e decorrente da própria ação. $\mathrm{O}$ autor acredita que a análise da performance de profissionais competentes poderá contribuir para uma boa formação profissional. Defende a inclusão de um forte componente de reflexão com base em situações práticas reais, como uma via possível para o profissional sentir-se capaz de enfrentar as situações novas e tomar as decisões adequadas, na vida profissional futura.

Schön (1992), ao considerar o professor como um profissional prático reflexivo, distingue três componentes diferentes que integram o pensamento prático: conhecimento na ação, reflexão na ação e reflexão sobre a ação. Entendendo a reflexão como a tomada de consciência do próprio conhecimento, é possível, a partir dela, construir novos conhecimentos ou reelaborar conhecimentos já existentes. Na educação, o olhar distanciado sobre o objeto de aprendizagem (do que e do como ensinar) permite ao professor refletir, e estabelecer confronto entre seu conhecimento prévio deste objeto e a nova aprendizagem, levando-se, assim, à construção de um novo conhecimento (ALARCÃO, 1996; DARSIE, CARVALHO, 1996).

Todos estes autores apresentam fundamentos e argumentos para sustentar que a formação de professores adequada necessita de uma reflexão crítica sobre a formação ambiental recebida pelo futuro docente, e necessita, também, da adoção de atividades investigativas que possibilitem a construção do conhecimento e favoreçam o desenvolvimento da autonomia. Para o desenvolvimento da proposta curricular que estamos apresentando neste trabalho, adotamos esses pressupostos teóricos. A investigação esteve guiada pelo modelo de formação destinado à progressão do conhecimento profissional do professor. Adotamos, como categoria de análise, a classificação de modelos didáticos de Porlán e Rivero (1998), baseada em concepções epistemológicas do conhecimento.

\section{Desenvolvimento metodológico: estudos de caso na formação inicial de professores}

A proposta de formação inicial de professores de Física está organizada com apoio do EVA, estruturada para promover a integração da relação teoria-prática por meio da investigação de estudos de caso, relevantes na ação educativa.

Com base em um tema de interesse, o estudo é desenvolvido seguindo passos determinados, da forma como sugerem Carvalho e Gil-Pérez (2001). Situações problemáticas são selecionadas da prática dos professores, para que os futuros professores se motivem a estudálas. Seguem, pelo menos, três passos, durante a busca de solução para as questões apresentadas. Inicialmente, o educando expõe suas concepções sobre as questões apresentadas e esboça uma hipótese de solução. Em seguida, é orientado a aprofundar seus conhecimentos com a leitura de um texto indicado e sintetizar as idéias do autor. Na etapa seguinte, ele deve buscar outras informações e propor uma segunda solução para os problemas levantados. Cada passo é acompanhado de discussões realizadas em pequenos grupos e/ou com a turma. Os 
passos são comentados pelo professor, que busca ressaltar aspectos positivos ou negativos, podendo aceitar ou recusar a resposta do estudante.

Este artigo apresenta a estrutura da disciplina Estratégia de Ensino I, que faz parte da proposta curricular, desenvolvida durante três semestres letivos, e analisa parte dos resultados obtidos na implementação da disciplina. São apresentadas as concepções iniciais e finais dos licenciandos no estudo de caso "Uma boa aula de Física".

\section{Desenvolvimento da proposta disciplinar}

A proposta disciplinar que compõe o currículo de um curso de licenciatura em Física tem, como objetivo, o desenvolvimento do conhecimento profissional do professor de Física a partir da reflexão sobre problemas da prática docente, da apropriação dos conhecimentos teóricos disponíveis e da elaboração de propostas de solução para os problemas selecionados. O conteúdo disciplinar é constituído por problemas selecionados com base na prática docente, nos materiais de apoio e nas interações entre os professores e os participantes, na busca de soluções para os estudos de caso. A metodologia de aprendizagem adotada, baseada em casos, requer a experimentação de hipóteses e a defesa das propostas de solução, pois os alunos partem de idéias prévias e articulam diferentes conhecimentos teóricos e práticos visando propor soluções.

Os estudos de caso são instrumentos deflagradores da discussão dos temas selecionados. Os casos são apresentados no formato de um relato de situações vivenciadas por professores e requerem o encaminhamento de uma solução. Os estudantes são solicitados a expor suas idéias e aprofundá-las por meio de uma sucessão de três ou quatro passos. A Tabela 1 apresenta a descrição do que se espera que os estudantes e professores façam ao longo da seqüência de passos do estudo.

Durante um estudo de caso são promovidas atividades presenciais e a distância, com apoio do ambiente de aprendizagem e suporte da Internet. Cada estudo de caso inicia com uma atividade de motivação sobre o assunto e uma leitura inicial do caso. Os alunos respondem ao primeiro passo com seus saberes iniciais. Ao longo do primeiro passo, os professores/tutores apresentam o tema de estudo e, justificando a escolha, motivam os alunos e sugerem leituras em grupo do caso. No ambiente virtual de aprendizagem, avaliam a coerência das respostas e orientam os estudantes na busca de elementos para superar suas concepções iniciais.

No segundo passo, são indicados os materiais de leitura e recomendado um texto para elaboração de uma resenha. Os professores/tutores verificam se o estudante foi capaz de perceber as principais idéias envolvidas no texto, e orientam discussão presencial, destacando pontos relevantes. No terceiro passo, os professores/tutores trabalham em sala de aula contrapondo as soluções propostas. No ambiente virtual, a solução do estudo é aprovada ou sua modificação pode ser solicitada. O último passo, nem sempre solicitado, corresponde à elaboração e implementação de atividade didática. Os professores/tutores orientam o desenvolvimento dos planejamentos, produzem avaliação das intervenções didáticas e conduzem o processo de avaliação.

O primeiro estudo de caso, "Uma boa aula de Física", foi realizado sem apoio do EVA, para que os estudantes se familiarizassem com a metodologia de aprendizagem baseada em casos, antes da utilização do ambiente virtual. Uma oficina de apresentação do ambiente 
Linhares, M. P.; Reis, E. M.

virtual foi realizada antes dos outros estudos de caso da disciplina: "O currículo de Física: contexto e reflexões" e "Rita e as rotações".

Tabela 1. Fases metodológicas dos estudos de caso.

Atividades dos estudantes Atitudes dos professores

Passo 1

Identificação das

concepções iniciais dos

estudantes.
- Leitura dos casos;

- Exposição no EVA das idéias próprias sobre as questões inquiridas.
Passo 2

Leitura e elaboração de resenha sobre texto (s) de referência.
Passo 3

Reestruturação dos conhecimentos e construção dos saberes profissionais

Passo 4

Elaboração e Implementação de atividade (s) didática (s).

\author{
- Leitura do (s) texto (s) de \\ referência; \\ - Elaboração de resenha do \\ texto principal; \\ - Contraste em grupo das \\ resenhas visando identificar \\ interesses comuns e \\ divergências.
}

- Releitura do caso e proposta de solução à luz de novos conhecimentos.

\author{
- Preparação do planejamento \\ e da atividade didática; \\ - Intervenção didática sobre \\ um tema selecionado durante \\ o estudo; \\ - Atividade unificadora da \\ visão dos estudantes sobre \\ um tema estudado.
}

- Apresentação com justificativa do tema do estudo (presencial);

- Motivação - leitura conjunta dos Casos (presencial);

- Avalia coerência das respostas no EVA;

- Aprova ou solicita modificação;Caracterização das concepções dos estudantes.

- Indica material de leitura e solicita resenha do texto base;

- Verifica formatação da resenha;

- Orienta sobre alterações necessárias;

- Aprova mudança de passo; - Orienta discussão presencial sobre o texto destacando pontos relevantes.

- Aprova ou sugere alterações na proposta de solução do estudo; - Orienta discussão presencial contrapondo soluções propostas; - Orienta processos de unificação de respostas.

- Orienta planejamentos sobre temas escolhidos pelos estudantes;

- Produz avaliação das intervenções didáticas; - Conduz processo de avaliação conjunta do estudo.

\section{Seleção de estudos de caso}

A seleção dos estudos de caso esteve orientada por elementos de uma postura investigativa e crítica. Na primeira das três disciplinas, consideramos um conjunto de três estudos de caso como a parte principal desta experiência didática. Os textos foram redigidos com base em questões realísticas (REIS, LINHARES, 2005b) e refletem interesses imediatos dos professores, considerando-se as orientações da área de pesquisa em ensino de Física. A Tabela 2 apresenta o tema selecionado, seu objetivo, texto principal para leitura, resenha e sua justificativa. 
Estudos de caso como estratégia de ensino...

Tabela 2. Estudos de caso da disciplina Estratégia de Ensino I.

\begin{tabular}{|c|c|c|c|c|}
\hline & Título & Objetivo & Texto para resenha & Justificativa \\
\hline 1 & $\begin{array}{l}\text { Uma boa aula de } \\
\text { Física }\end{array}$ & $\begin{array}{l}\text { Apresentar novas idéias } \\
\text { sobre educação para } \\
\text { enriquecer o conhecimento e } \\
\text { contribuir para a } \\
\text { argumentação sobre o tema. }\end{array}$ & $\begin{array}{l}\text { Os novos pensadores } \\
\text { da educação } \\
\text { (MARANGON, LIMA, } \\
\text { 2002) }\end{array}$ & $\begin{array}{l}\text { Como primeira leitura, o artigo da } \\
\text { revista Nova Escola apresenta as } \\
\text { idéias de Morin, Perrenoud, Coll, } \\
\text { Nóvoa, Hernández e Toro, em } \\
\text { linguagem simples e adequada. }\end{array}$ \\
\hline 2 & $\begin{array}{l}\text { O currículo de } \\
\text { Física: contexto e } \\
\text { reflexões }\end{array}$ & $\begin{array}{l}\text { Elevar o patamar de } \\
\text { entendimento dos estudantes } \\
\text { sobre a complexidade das } \\
\text { construções curriculares. }\end{array}$ & $\begin{array}{l}\text { A contribuição da } \\
\text { Física para um novo } \\
\text { Ensino Médio } \\
\text { (KAWAMURA, } \\
\text { HOUSOME, 2003) }\end{array}$ & $\begin{array}{l}\text { O artigo da revista A Física na } \\
\text { Escola comenta a proposta de um } \\
\text { novo Ensino Médio e o currículo } \\
\text { de Física indicado no PCN+. }\end{array}$ \\
\hline 3 & Rita e as rotações & $\begin{array}{l}\text { Aprofundar o conhecimento } \\
\text { básico sobre as rotações e } \\
\text { produzir atividades didáticas. }\end{array}$ & $\begin{array}{l}\text { Uma estética do } \\
\text { espaço e do tempo } \\
\text { (MENEZES, 2005) }\end{array}$ & $\begin{array}{l}\text { Apesar de ser um tema da Física } \\
\text { clássica e fazer parte do } \\
\text { cotidiano dos alunos, eles têm } \\
\text { pouca familiaridade com o } \\
\text { assunto. No capítulo "Uma } \\
\text { estética do espaço tempo" o autor } \\
\text { apresenta um estudo do } \\
\text { movimento e as simetrias do } \\
\text { espaço e descreve os } \\
\text { movimentos de translação e } \\
\text { rotação. }\end{array}$ \\
\hline
\end{tabular}

"Uma boa aula de Física" foi o primeiro tema selecionado. A idéia é conhecer o que pensam os licenciandos sobre o papel do professor e como se posicionam em relação a uma análise crítica sobre uma aula de Física. Além disso, é um tema favorável a promover o início do debate sobre educação e ensino de Física, priorizando uma situação familiar a todos os estudantes. Focado nas aulas geralmente observadas no Ensino Médio, pode ser um tema gerador de discussões sobre o próprio tipo de aula que os licenciandos têm na universidade.

O segundo estudo de caso, "O currículo de Física: contexto e reflexões", busca elevar o patamar de entendimento dos estudantes sobre a complexidade da construção curricular, no sentido de promover uma discussão ampla sobre o desenho das estruturas curriculares, que vão além dos programas que os professores utilizam nas diversas disciplinas (SACRISTÁN, 2000). O estudo favoreceu a discussão de fatores que contribuem para a organização curricular e o conhecimento dos PCNs da área de Ciências da Natureza e Matemática, em especial, da Física.

O terceiro estudo de caso, denominado "Rita e as rotações", está voltado para uma típica situação de ensino, o estágio curricular, onde a vivência do professor está em jogo. Também reconhecemos que o conteúdo disciplinar tem sido pouco estudado, tanto no Ensino Médio quanto nas licenciaturas em Física, apesar da importância contextual de suas decor- 
rências científicas e tecnológicas. Por isso, a culminância desse estudo apontou para o planejamento de uma atividade didática, no formato de uma aula sobre conteúdos relacionados ao tema (quarto passo). Apesar de ser um estudo da Física clássica e fazer parte do cotidiano dos alunos, estes apresentam pouca familiaridade com o assunto.

\section{Desenvolvimento da pesquisa: instrumentos e análise}

O estudo sobre concepções didáticas dos futuros professores foi o foco da investigação. O público alvo desta pesquisa foi uma turma de 21 estudantes matriculados na disciplina Estratégias de Ensino I. Analisaram-se os resultados correspondentes aos 14 estudantes que finalizaram os três passos do estudo de caso "Uma boa aula de Física", apresentado na Tabela 3.

Tabela 3. Estudo de caso "Uma boa aula de Física".

O jovem Albieri que faz o curso de Física em uma universidade pública, reflete sobre as aulas que assiste e as outras aulas de Física e Ciências que já assistiu ao longo de sua vida escolar. Percebe que tem boas e más lembranças e, como se encaminha para a profissão docente, se indaga sobre que tipos de aulas de Física são satisfatórias. A partir daí, considerando aspectos diversos, como por exemplo, os vários professores que teve as escolas onde estudou, as técnicas que foram empregadas, os livros didáticos usados, a curiosidade despertada, as tecnologias que foram usadas ou não, etc., se pergunta: O que é uma boa aula de Física? Por que quero ser professor de Física?

Os instrumentos da pesquisa utilizados para análise das concepções dos estudantes sobre ensino e docência foram os textos contendo respostas para as questões levantadas no estudo de caso. A análise do estudo de caso "O currículo de Física: contexto e reflexões" foi realizada em outra publicação (REIS, LINHARES, 2006), e os resultados do caso "Rita e as rotações" estão sendo avaliados em outro artigo ainda não concluído.

Para o encaminhamento da pesquisa, optamos por uma abordagem relacionada ao tipo de investigação participativa que adotamos no contato direto com estudantes. Assumimos as referências de uma pesquisa-ação onde nossas intervenções como pesquisadores influenciam o contexto educativo. A seqüência de três passos favorece o entendimento sobre o encaminhamento das idéias dos estudantes, revelando um possível avanço nestas idéias.

Os textos foram segmentados buscando identificar unidades de significação (valores, atitudes, visões e opiniões) (BARDIN, 1994). Para proceder à análise qualitativa, preenchemos

\footnotetext{
${ }^{5} \mathrm{O}$ artigo "Uso de um espaço virtual de aprendizagem na formação inicial de professores de Física: estudando o currículo de Física", foi apresentado no X Encontro de Pesquisa em Ensino de Física, de 15-19 ago. 2006, em Londrina.
} 
uma planilha para cada estudante. No primeiro momento, foi feita uma leitura do passo $1 \mathrm{e}$, a seguir, do passo 3. Procurou-se identificar avanços conceituais nas concepções sobre conhecimento prático do professor, após o desenvolvimento de atividades que favorecessem mudanças relativas à inovação curricular, realizadas no passo intermediário.

Neste artigo, apresentamos, inicialmente, as análises dos dados de dois alunos representativos do grupo, contrapondo as idéias iniciais e finais sobre metodologia, conteúdo didático e ambiente de trabalho, visando aprofundar os procedimentos adotados. Na etapa final, agrupamos os dados do conjunto (14 alunos) com a finalidade de avaliar a evolução do grupo relativa aos aspectos selecionados, utilizando, como referencial, a proposta evolutiva do conhecimento dos professores (PORLÁN, RIVERO, 1998).

A Tabela 4 apresenta uma síntese das principais idéias da teoria do conhecimento do professor, relativas ao conhecimento prático, que guiou a análise das respostas dos futuros professores ao estudo de caso. Pretende-se, assim, avaliar as concepções dos futuros professores, após as interações em sala de aula e com os materiais consultados, comparando com os elementos característicos dos quatro modelos didáticos de referência descritos por Porlán e Rivero (1998).

A organização do conhecimento, apresentada na Tabela 4, está baseada em teorias epistemológicas gerais, que destacam o conhecimento escolar como: um produto acabado e formal (modelo didático tradicional); um produto acabado e um processo técnico (modelo didático tecnológico); um produto aberto gerado em um processo instantâneo (modelo didático espontaneísta); um produto aberto gerado em um processo construtivo orientado (modelo didático investigativo). Os estágios de desenvolvimento do conhecimento dos professores estão relacionados aos modelos didáticos, cujas características permitem avaliar a etapa do processo de reorganização do conhecimento docente dos alunos investigados.

\section{Análise dos resultados}

Descrevemos as atividades relacionadas ao primeiro estudo de caso da disciplina Estratégias para o Ensino de Física I e analisamos a evolução inicial das concepções didáticas dos futuros professores. Como objetivo do estudo, foi destacado conhecer e analisar as próprias idéias em relação ao ensino de Física e contrastar o ponto de vista pessoal com aqueles que procedem da investigação didática e da experiência docente. Na Tabela 5, estão relacionados os segmentos ou unidades de significação extraídas das respostas do aluno A às questões que encerram o estudo de caso: "O que é uma boa aula de Física?" e "Por que quero ser professor de Física?"

No passo inicial, o aluno A fez comentários sobre metodologia e conteúdo, com características dos modelos tradicionais e espontaneísta: os conteúdos disciplinares devem estar apoiados na adoção de um bom livro didático, relacionados com fatos do cotidiano e demonstrados por aulas experimentais. A metodologia adequada é aquela que desperta a atenção do aluno e estabelece uma boa relação professor-aluno. $\mathrm{O}$ apego à organização disciplinar dos conteúdos e o apoio do livro didático são típicos do modelo didático dominante. No estágio de transição, é comum os professores expressarem o desejo de responder aos interesses e experiências dos alunos. Não há preocupação em explicitar teorias psicopedagó- 
Linhares, M. P.; Reis, E. M.

gicas que fundamentem o ensino. Nesta visão, a experiência, o interesse e o contato com a vida cotidiana permitem aos alunos se apropriarem dos conhecimentos.

Tabela 4. Modelos didáticos de referência*

\begin{tabular}{|c|c|c|c|c|}
\hline & & Modelos & de transição & \\
\hline & tra & Tecnológico & Espontaneísta & - \\
\hline $\begin{array}{c}\text { Fins } \\
\text { Educativos }\end{array}$ & $\begin{array}{l}\text { Adaptação social dos } \\
\text { alunos, } \\
\text { doutrinamento } \\
\text { cultural; transmissão } \\
\text { de valores } \\
\text { dominantes. }\end{array}$ & $\begin{array}{l}\text { Idéia de neutralidade } \\
\text { e de ensinar } \\
\text { adequadamente as } \\
\text { ciências associadas. }\end{array}$ & $\begin{array}{l}\text { Felicidade dos alunos e } \\
\text { uma formação adequada } \\
\text { para desenvolver a vida } \\
\text { cotidiana de forma } \\
\text { autônoma e crítica. }\end{array}$ & $\begin{array}{l}\text { Formação integral dos } \\
\text { alunos como futuros } \\
\text { cidadãos; contribuições } \\
\text { da ciência para esta } \\
\text { formação. }\end{array}$ \\
\hline Conteúdos & $\begin{array}{l}\text { Ciência como } \\
\text { referente único; } \\
\text { seqüências estáticas } \\
\text { e rígidas; conteúdos } \\
\text { desconectados com } \\
\text { a realidade dos } \\
\text { alunos. }\end{array}$ & $\begin{array}{l}\text { Organização em } \\
\text { função de objetivos } \\
\text { rígidos; ciência como } \\
\text { referente básico do } \\
\text { conhecimento } \\
\text { escolar; são } \\
\text { consideradas } \\
\text { variáveis } \\
\text { psicológicas. }\end{array}$ & $\begin{array}{l}\text { Importância aos } \\
\text { procedimentos e atitudes; } \\
\text { organização atende aos } \\
\text { interesses dos alunos; } \\
\text { programação pouco } \\
\text { sistemática; improvisação } \\
\text { no tratamento dos } \\
\text { conteúdos. }\end{array}$ & $\begin{array}{l}\text { Integração ao cotidiano, } \\
\text { social, científico e } \\
\text { ideológico; organização } \\
\text { sistemática, explícita e } \\
\text { flexível; integração de } \\
\text { conceitos, atitudes e } \\
\text { procedimentos. }\end{array}$ \\
\hline Metodologia & $\begin{array}{l}\text { Transmissão verbal } \\
\text { do professor e uso } \\
\text { quase exclusivo do } \\
\text { livro texto; escasso } \\
\text { protagonismo do } \\
\text { aluno. }\end{array}$ & $\begin{array}{l}\text { Planejamento } \\
\text { rigoroso; reprodução } \\
\text { do método científico } \\
\text { empirista; } \\
\text { protagonismo dos } \\
\text { alunos na execução } \\
\text { de atividades, mas } \\
\text { não no planejamento. }\end{array}$ & $\begin{array}{l}\text { Planejamento genérico, } \\
\text { baseado em ensaio e } \\
\text { erro; recursos didáticos } \\
\text { diversificados usados de } \\
\text { forma assistemática; } \\
\text { alunos participam no } \\
\text { desenho e no } \\
\text { desenvolvimento das } \\
\text { tarefas. }\end{array}$ & $\begin{array}{l}\text { Investigação orientada } \\
\text { de problemas } \\
\text { selecionados; atividades } \\
\text { diversificadas baseadas } \\
\text { em estratégias } \\
\text { construtivistas; idéias e } \\
\text { experiências dos alunos } \\
\text { como eixo organizador } \\
\text { da intervenção do } \\
\text { professor. }\end{array}$ \\
\hline Avaliação & $\begin{array}{l}\text { Grau de } \\
\text { memorização } \\
\text { mecânica dos } \\
\text { conteúdos; } \\
\text { mecanismo de poder. }\end{array}$ & $\begin{array}{l}\text { Medidas rigorosas em } \\
\text { função dos objetivos } \\
\text { programados; provas } \\
\text { objetivas (pré e pós- } \\
\text { testes). }\end{array}$ & $\begin{array}{l}\text { Avalia-se a dinâmica da } \\
\text { aula através da } \\
\text { participação dos alunos e } \\
\text { das observações do } \\
\text { professor; a } \\
\text { aprendizagem dos alunos } \\
\text { não é objeto direto de } \\
\text { avaliação. }\end{array}$ & $\begin{array}{l}\text { Contínua e processual } \\
\text { baseada em diversos } \\
\text { instrumentos; avalia-se a } \\
\text { evolução das idéias dos } \\
\text { alunos, a dinâmica de } \\
\text { classe, as hipóteses } \\
\text { curriculares e a } \\
\text { intervenção do professor }\end{array}$ \\
\hline
\end{tabular}

* Adaptada de Porlán e Rivero (1998). 
Estudos de caso como estratégia de ensino...

Tabela 5. Unidades de significação extraídas do texto do aluno A.

O que é uma boa aula de Física?

\section{Passo inicial}

. desperta o interesse do aluno;

- traz fenômenos ou fatos do cotidiano para discussão;

- deve estar apoiada na adoção de um bom livro didático;

- precisa de boa relação professor-aluno;

- são necessárias aulas experimentais que vão mostrar na prática assuntos vistos em sala de aula.
Passo final

. envolve práticas em sala de aula;

- necessita de uma boa relação professor-aluno;

- o professor deve ter suficiente competência para

ministrar aulas;

- responde com seus deveres;

- passa conteúdo de forma consistente e de acordo com a necessidade da turma;

- deve se manter atualizado sobre novos temas e tecnologias que o ajudarão na aula;

. contextualizar o ensino;

- uma boa aula é aquela que o aluno mais aprende, não aquela em que o professor falou muito.

\section{Por que quero ser professor de Física?}

\section{Passo inicial}

- porque tive uma professora que fazia a relação da Física com o cotidiano muito bem e despertava o interesse da turma;

- é uma matéria que me interessa muito;

- a profissão permite ver a formação do aluno e de um cidadão;

- para ajudar a quebrar a barreira entre os alunos e a Física, despertando interesse e abrindo oportunidades.

Passo final

$\mathrm{Na}$ resposta final, foi ressaltado que mantinha a idéia inicial de que são necessárias aulas práticas e uma boa relação professor-aluno, mas também explicita que percebeu outros importantes itens e qualidades, os quais sem eles, "uma aula não seria suficientemente boa". O aluno A acrescenta, às idéias iniciais, preocupação quanto à atualização do professor sobre novos temas e tecnologias. Deve ser um profissional competente e "responder com seus deveres". Podese supor que há uma demonstração de interesse em mudanças na prática docente, visando inovações curriculares possíveis em sala de aula. Isso sugere uma tomada de consciência da própria visão de ensino. Na sua resposta final, também estão presentes outras características de um modelo de transição, enfatizando a aprendizagem do aluno, "uma boa aula é aquela que o aluno mais aprende não aquela em que o professor falou muito".

Em relação à outra pergunta, "Por que quero ser professor de Física", o aluno não fez menção no passo final. No passo inicial ressaltou, como determinante para sua escolha de estudar Física, a experiência no Ensino Médio, com uma professora que fazia bem a relação da Física com o cotidiano, despertando o interesse de toda a turma para o assunto tratado. Exemplificou com duas experiências simples que nunca mais esqueceu: uma reprodução da 
gaiola de Faraday e uma demonstração das linhas de campo magnético, com ímã e limalha de ferro. Expressa um saber gerado durante toda a formação escolar em processos de impregnação ambiental. É um aluno motivado com a profissão e percebe que o professor deve contribuir para uma formação cidadã do aluno.

A Tabela 6 apresenta os dados do aluno B, o outro aluno selecionado para representar as idéias do grupo sobre questões relativas à prática docente.

O aluno B destacou no passo inicial, em relação aos conteúdos, o domínio da matéria pelo professor, sem fazer referência a outros requisitos, evidenciando predominância da lógica disciplinar de organização curricular. Refere-se à capacidade do professor de transmissão da matéria, mas não faz considerações sobre a participação dos alunos na aprendizagem. São idéias predominantes do modelo tradicional.

Tabela 6. Unidades de significação extraídas do texto do aluno B

\section{O que é uma boa aula de Física?}

\section{Passo inicial}

- atende a necessidade do aluno;

- usa materiais didáticos capazes de despertar o interesse dos alunos;

- está relacionada com o domínio do professor sobre a disciplina;

- está relacionada com a capacidade do professor de transmiti-la;

- está relacionada com recursos tecnológicos utilizados;

- o quadro e giz possibilitam visualizar a teoria presente nos livros;

- deveria englobar a elaboração de projetos com o objetivo de proporcionar uma forma agradável de estudar.
Passo final

- deve ter planejamento detalhado;

- percebe a sala de aula como um espaço heterogêneo que deve ser compreendido e valorizado

- atividades que façam o aluno raciocinar, e não decorar fórmulas;

- uso de tecnologias como software que simulem situações do dia-a-dia;

- aborda evolução dos conceitos trabalhados, origem das idéias que fundamentam a teoria; - realização de eventos no âmbito escolar para a interação de conhecimentos com a prática; - incentiva os alunos a expressarem seus conhecimentos tácitos;

- promove a interação professor-aluno;

- promove a interligação dos conhecimentos;

. trabalha com a interdisciplinaridade.

\section{Por que quero ser professor de Física?}

\section{Passo inicial}

- porque tive bons professores que despertaram minha curiosidade, realizaram práticas no laboratório; criaram um ambiente que prendia o aluno para a matéria e trabalharam curiosidade do cotidiano;

- o professor não pode esquecer de capacitar o aluno para o mercado de trabalho.
Passo final

- gosto muito da matéria;

- me sinto bem com as pessoas;

- o professor pode contribuir para realização de sonhos dos alunos. 
Em relação à metodologia, acrescenta a importância do uso de materiais diversificados e do uso de recursos tecnológicos, para despertar a atenção do aluno acrescenta ainda que apesar da importância dos recursos tecnológicos, o quadro e o giz não devem ser deixados de lado, pois "possibilitam visualizar a teoria presente nos livros". Explicita a importância de incluir a elaboração de projetos para proporcionar um estudo mais agradável. Percebe-se que o aluno B tem consciência de que é preciso promover inovações curriculares, mas a justificativa é a motivação do aluno. Essas concepções evidenciam conhecimentos característicos dos modelos de transição.

Depois do estudo, refere-se à necessidade de novas idéias para tornar mais atrativo o ensino de Física, entendendo a sala de aula como um espaço heterogêneo que deve ser compreendido e valorizado. $\mathrm{O}$ aluno traz outras concepções sobre metodologia e conteúdo mais evoluídas, destacando: a interação do conhecimento com a prática, o uso do conhecimento tácito do aluno, a importância da interação professor-aluno, a interligação dos conhecimentos e o trabalho interdisciplinar. Todos esses aspectos estão presentes nos modelos alternativos, embora ainda se apresentem de forma pouco sistemática. As marcas do referencial teórico explicitadas nas respostas do aluno B permitem avaliar que houve interesse pelo estudo e evolução das concepções iniciais.

Quanto a ser professor, o aluno traz boas lembranças de seus professores, destacando a necessidade de "capacitar os alunos para o mercado de trabalho". Faz referência ao passado no passo inicial, como: "tive bons professores de Física", e ao futuro no passo final: "poder contribuirpara realização de sonhos dos alunos". Isso indica uma mudança de postura no discurso, pois, no passo inicial, fala como aluno e, no passo final, como um futuro professor.

A Tabela 7 apresenta uma síntese das idéias do grupo de participantes.

As respostas de todos os alunos ao estudo de caso foram inicialmente analisadas em separado. Numa etapa posterior, para que o processo de organização dos resultados não se tornasse repetitivo, optamos por elaborar uma síntese das idéias principais relativas ao conhecimento prático do professor: conteúdos, metodologia e ambiente de trabalho (Tabela 7). A análise foi realizada contrapondo as idéias finais e iniciais, após as interações em sala de aula e com os materiais didáticos consultados, com a finalidade de avaliar a evolução do grupo relativa aos aspectos característicos dos quatro modelos didáticos de referência.

A organização da Tabela 7 considera os modelos didáticos de referência e suas categorias relativas aos problemas da prática docente: conteúdos, metodologia, fins educativos e avaliação (PORLÁN, RIVERO, 1998). Os dois últimos aspectos não estão presentes explicitamente nas respostas dos participantes e, por isso, não foram considerados. Entretanto, outra categoria foi criada, ambiente de trabalho, devido às constantes referências ao ambiente favorável que o professor deve saber criar para promover a aprendizagem dos alunos. Esta categoria foi separada dos aspectos metodológicos.

Os saberes iniciais do grupo de futuros professores indicam predominância de concepções relacionadas com suas vivências anteriores como alunos no Ensino Básico. Nas suas respostas iniciais, não estão presentes elaborações teóricas relacionadas aos conteúdos que já foram estudados em outras disciplinas pedagógicas do currículo do curso de licenciatura, como, por exemplo, a didática ou a psicologia da educação.

Da análise da fala coletiva do grupo, destacamos algumas concepções iniciais mais freqüentes sobre uma boa aula de Física. Relacionadas aos conteúdos: necessidade do profes- 
sor dominá-los, uso do livro didático como referência principal; utilizar fatos do cotidiano, enfatizar os conceitos em detrimento das fórmulas e saber transmiti-los aos alunos. Em relação aos conteúdos, as idéias são tradicionais quanto à adoção de um livro didático que estabelece o que ensinar, mas apresentam outras idéias que revelam o estágio de transição, tais como: ênfase em procedimentos, atitudes e organização, que atende aos interesses dos alunos.

Quanto à metodologia, os alunos indicam, como fatores essenciais para uma boa aula: resolução de exercícios, realização de aulas experimentais, utilização de bons materiais didáticos e recursos tecnológicos, preparação de aulas objetivas; adequação do plano de aula às características dos alunos e elaboração de projetos. As concepções de um modelo espontaneísta são reveladas quando enfatizam recursos didáticos diversificados sem mencionar o planejamento adequado ou o protagonismo dos alunos nas aulas, sem especificar os métodos de trabalho. Concepções marcantes do modelo tecnológico estão presentes na ênfase do trabalho experimental e na objetividade das aulas, que permite identificar uma visão empírica de ciências.

Tabela 7. Síntese das idéias do grupo de participantes do estudo de caso "Uma boa aula de Física".

\begin{tabular}{|c|c|c|}
\hline & Passo inicial & Passo final \\
\hline Conteúdos & $\begin{array}{l}\text { Aborda fatos do cotidiano; livro } \\
\text { didático como referência principal; } \\
\text { professor deve dominar os } \\
\text { conteúdos; ênfase em conceitos em } \\
\text { detrimento de fórmulas; saber } \\
\text { transmitir aos alunos. }\end{array}$ & $\begin{array}{l}\text { Conteúdos de acordo com as necessidades dos } \\
\text { alunos; trabalha com projetos; estreita as relações } \\
\text { entre Física e outras disciplinas; respeita o rigor } \\
\text { científico sem tornar o conhecimento inatingível } \\
\text { para os alunos; apresenta conteúdos de forma } \\
\text { complexa e não reducionista; avalia a contribuição } \\
\text { dos conhecimentos da Física para as tecnologias. }\end{array}$ \\
\hline Metodologia & $\begin{array}{l}\text { Aulas experimentais, objetivas e com } \\
\text { muitos exercícios; recursos visuais } \\
\text { variados; bons materiais didáticos; } \\
\text { recursos tecnológicos; foco na } \\
\text { aprendizagem; elaboração de } \\
\text { projetos. }\end{array}$ & $\begin{array}{l}\text { Práticas em sala de aula; ensino contextualizado; } \\
\text { métodos de ensino variados; recursos humanos e } \\
\text { tecnológicos variados; planejamento didático } \\
\text { detalhado; evita que os alunos decorem fórmulas; } \\
\text { prioriza a aprendizagem; temas diversificados e } \\
\text { tecnologias atualizadas; Física como uma ciência } \\
\text { que evolui; realiza eventos no âmbito escolar para } \\
\text { proporcionar a relação teoria prática; incentiva os } \\
\text { alunos a expressarem seus conhecimentos tácitos; } \\
\text { promove interligação dos conhecimentos; adota } \\
\text { ensino interdisciplinar. }\end{array}$ \\
\hline
\end{tabular}

\begin{abstract}
Ambiente Desperta o interesse e curiosidade de trabalho aluno; promove uma boa relação professor-aluno; visa o bem estar do aluno; atende seus interesses; proporciona uma forma agradável de estudar; incentiva a participação do aluno; professor dinâmico criativo e carismático.

Boa relação professor aluno; professor atualizado e competente; foco na aprendizagem e participação do aluno; professor conhece o aluno e garante sua participação; promove a identificação dos alunos com o professor; ênfase na relação humana; promove o desenvolvimento do aluno; desperta pensamento crítico e útil nos alunos; interação entre os professores da escola; professor interado com o ambiente escolar.
\end{abstract}


Em relação ao ambiente de trabalho, o professor deve ser dinâmico, criativo e carismático, adotar uma postura adequada e ser capaz de: despertar o interesse e curiosidade do aluno, produzir bem-estar aos alunos, estabelecer boa relação professor-aluno; incentivar a participação do aluno e proporcionar uma forma agradável de estudar. Estas idéias revelam mais o ponto de vista do aluno que do professor, o desejo de aulas melhores do que aquelas que tiveram.

Os alunos acrescentaram ou modificaram suas idéias iniciais sobre uma boa aula, depois do trabalho na disciplina, leitura de textos indicados, resenhas, interação com o professor por meio do ambiente virtual e discussões presenciais. Em relação aos conteúdos didáticos, destacamos as idéias mais elaboradas que não estiveram presentes no passo inicial: conteúdos apresentados de forma complexa e não reducionista; estreita relação entre Física e outras disciplinas; respeito ao rigor científico sem tornar o conhecimento inatingível para os alunos; avaliação da contribuição dos conhecimentos da Física para as tecnologias. Embora não justifiquem com argumentos sólidos, percebe-se que as novas idéias surgiram após as interações, algumas presentes no modelo didático de referência ou modelo investigativo.

Quanto à metodologia, as novas idéias incorporadas fazem referência à utilização de recursos humanos e tecnológicos variados e de planejamento de ensino contextualizado e detalhado. Ressaltam que a Física deve ser apresentada como uma ciência que evolui em conjunto com outras, e que se devem realizar eventos no âmbito escolar para proporcionar a relação entre teoria e prática. Deve-se incentivar os alunos a expressarem seus conhecimentos tácitos e expor teorias intercaladas com situações que gerem discussão e participação.

À dimensão didática ambiente de trabalho, os licenciandos acrescentaram que é preciso conhecer o aluno e garantir a participação de toda a turma; alcançar a identificação dos alunos com o professor; valorizar a relação humana; despertar nos alunos pensamento crítico e útil. Para uma prática docente de qualidade, os estudantes também relacionaram algumas atitudes necessárias aos professores: responsabilidade com seus deveres; intercâmbio de experiências com outros professores; atualização permanente; interesse pelo ambiente escolar.

Essas análises do grupo revelaram que os estudantes procuraram elaborar soluções incorporando conhecimentos teóricos disponíveis após a reflexão sobre os problemas da prática docente apresentados e da interação com o professor e com a turma. Pode-se avaliar que houve evolução das concepções iniciais do grupo sobre saberes necessários à prática docente de qualidade.

Alguns estudantes, entretanto, não mostraram interesse pelo estudo ou o estudo realizado pouco influenciou suas concepções. Um exemplo de solução final inconsistente é de uma afirmação que "a relação humana é a mais importante para uma boa aula e que todas as formas de auxílio são válidas". Este aluno acrescentou que, apesar de ter vontade de ser o professor que desejou para o seu Ensino Médio, não tem vocação para o ensino, mas se for o caso, não quer ser um "professor durão, que está ali com uma caneta azul o outra vermelha e quem decora o que ele fala fica azul, caso contrário vermelho". Está fazendo menção ao processo de avaliação tradicional, que rejeita e quer modificar. Assim como este aluno, outros apresentam uma postura ambígua em relação ao desejo de ser professor. Muitos têm bolsa de iniciação científica e pensam em ser pesquisadores; e, para isso, precisam investir apenas nas disciplinas específicas, que são aquelas que mais cobram investimento dos alunos, com provas tradicionais e longas listas de exercícios. 


\section{Considerações finais}

Neste trabalho, apresentamos a estrutura da primeira de uma série de três disciplinas do currículo de uma licenciatura em Física, e realizamos uma avaliação inicial da implementação da proposta didática. Partindo do pressuposto de que os futuros professores têm concepções sobre o conhecimento profissional docente, forjadas durante sua formação, que refletem modelos didáticos inadequados, elaboramos estudos para problematizar situações da prática docente e favorecer a conscientização e superação dessas idéias.

Foram analisadas as respostas às questões do estudo de caso: "O que é uma boa aula de Física" e "por que quero ser professor"? Os alunos apresentaram suas idéias iniciais e buscaram aprimorar seus conhecimentos percorrendo uma seqüência de passos orientados pelo professor.

Da análise realizada, percebe-se a disposição da maioria dos alunos para superar problemas da prática tradicional de ensino, caracterizada pela reprodução mecânica do conhecimento acadêmico. Suas concepções iniciais já trazem elementos do modelo de ensino tecnológico, que valoriza a dimensão prática da atividade docente, e do modelo espontaneísta, que enfatiza o conhecimento prático e desconsidera as contribuições teóricas para a progressão do conhecimento do professor (PÓRLAN, RIVERO, 1998).

Os elementos presentes nas respostas ao passo final permitem avaliar que parte dos alunos percebeu a importância desses estudos para superar obstáculos por meio de um processo de reorganização do conhecimento profissional. Com exceção de quatro alunos, dentre quatorze, que não acrescentaram idéias mais elaboradas em suas respostas finais, os demais incorporaram novas idéias, durante o estudo sobre uma boa aula de Física.

Este é um resultado satisfatório para o primeiro estudo de caso da disciplina Estratégias para o Ensino de Física I, pois, apesar do pequeno avanço conceitual, percebe-se avanço nas atitudes e consciência das próprias idéias: mostram-se críticos quanto à escolha da futura profissão; comprometem-se com mudanças na educação; estão conscientes da necessidade de permanente evolução profissional e da própria responsabilidade nesse processo, tal como apontado por Harres (2005).

Como parte dos resultados alcançados, relatamos o desenvolvimento de habilidades, como: leitura e interpretação de texto, expressão escrita e oral, argumentação coerente com suas opiniões, prática de trabalho colaborativo, busca de informações adequadas.

Em síntese, o estudo realizado - usando as etapas de evolução do conhecimento profissional do professor como referencial de avaliação das concepções sobre docência dos alunos da licenciatura em Física - ofereceu resultados que contribuíram para uma maior compreensão dos processos de implementação de inovações curriculares propostos durante a formação inicial. Espera-se avançar na proposta durante a formação inicial, favorecendo a evolução das idéias sobre a profissão com base na reflexão sobre problemas da prática docente e da apropriação dos conhecimentos teóricos disponíveis. 
Estudos de caso como estratégia de ensino...

\section{Referências}

ALARCÃO, I. Reflexão crítica sobre o pensamento de D. Schön e os programas de formação de professores. Revista da Faculdade de Educação, São Paulo, v. 22, n. 2, p. 11-42, 1996.

BARDIN, L. Análise de conteúdo. Lisboa: Edições 70, 1994.

BRASIL. Ministério da Educação e Cultura. Diretrizes Curriculares para a Formação de Professores da Educação Básica, em nível superior, curso de licenciatura, graduação plena. Brasília: CNE, 2001.

Secretaria de Educação Média e Tecnológica. Parâmetros Curriculares Nacionais para o Ensino Médio. Brasilia: MEC, 1999.

Lei de Diretrizes e Bases da Educação. Brasília: MEC, 1996.

CARVALHO, A. M. P; GIL-PÉREZ, D. E. Formação de professores de ciências:

tendências e inovações. São Paulo: Cortez, 2001. (Coleção Questões de Nossa Época. v. 26)

DARSIE, M. M. P.; CARVALHO, A. M. P. O início da formação do professor reflexivo.

Revista da Faculdade de Educação, São Paulo, v. 22, n. 2, p. 90-108, 1996.

FREIRE, P. A pedagogia da autonomia. 34. ed. Rio de Janeiro: Paz e Terra, 2000.

HARRES, J. B. S. et al. Laboratórios de ensino: inovação curricular na formação de professores de ciências. Santo André: ESETec, 2005. v. 1.

JONASSEN, D. O uso das novas tecnologias na educação a distância e a aprendizagem construtivista. Em Aberto, Brasília, v. 16, n. 70, p. 70-88, 1996.

KAWAMURA, M. R.; HOSOUME, Y. A contribuição da Física para o novo Ensino Médio. Física na Escola, São Paulo, v. 4, n. 2, p. 22-7, 2003.

KOMATSU, R. S.; ZANOLLI, M. B.; LIMA, V. V. Aprendizagem Baseada em Problemas. In: MARCONDES, E.; GONÇALVES, E. L. (Orgs.). Educação médica. Sâo Paulo: Sarvier, 1998.

KRASILCHIK, M. Formação de professores e ensino de ciências: tendências nos anos 90. In: MENEZES, L.C. (Org.). Formação continuada de professores no contexto iberoamericano. Campinas/São Paulo: Autores Associados/NUPES, 1996. p. 135-40.

MARANGON, C.; LIMA, E. Os novos pensadores da educação. Nova Escola, São Paulo, n. 154, p. 18-25, 2002.

MENEZES, L. C. A matéria uma aventura do espírito: fundamentos e fronteiras do conhecimento físico. São Paulo: Editora Livraria da Física, 2005. p. $6-8,2000$.

Uma Física para o novo Ensino Médio. Física na Escola, São Paulo, v. 1, n. 1,

(Org.). Formação continuada de professores no contexto ibero-americano. Campinas/São Paulo: Autores Associados/NUPES, 1996. 
Linhares, M. P.; Reis, E. M.

NÓVOA, A. (Org.). Os professores e a sua formação. Lisboa: Dom Quixote, 1992.

PAIXÃO LINHARES, M.; MACEDO REIS, E. Aprendendo a ensinar: a sala de aula como espaço de reflexão. In: INTERNATIONAL CONGRESO IN DIDÁCTICA DE LAS CIÊNCIAS, 7., 2005, Granada. Enseñanza de las Ciencias, v. extra, 2005.

PORLÁN, R.; RIVERO, A. El conocimiento de los profesores. Sevilla: Díada, 1998.

REIS, E. M.; LINHARES, M. P. Uso de um espaço virtual de aprendizagem na formação de professores de Física: estudando o currículo de Física. In: ENCONTRO DE PESQUISA EM ENSINO DE FÍSICA, 10., 2006, Londrina. Anais... Londrina: SBF, 2006. 1 CD-ROM.

- Convergências tecnológicas: redesenhando as fronteiras da formação de professores de ciências. In: ENCONTRO DE PESQUISA EM EDUCAÇÃO EM CIÊNCIAS, 5., 2005a, Bauru. Anais... Bauru: ABRAPEC, 2005. 1 CD-ROM.

Discutindo a ortodoxia do currículo de Física em um ambiente virtual para estudos de ciência. In: SIMPÓSIO NACIONAL DE ENSINO DE FÍSICA, 16., 2005b, Rio de Janeiro. Anais... Rio de Janeiro: SBF, 2005b. 1 CD-ROM.

Desafios de uma proposta construtivista na formação prático-reflexiva de professores de Física. In: ENCONTRO DE PESQUISA EM EDUCAÇÃO EM CIÊNCIAS, 4., 2003, Bauru. Anais... Bauru: ABRAPEC, 2003. 1 CD-ROM.

REZENDE, F.; OSTERMANN, F. Formação de professores de Física no ambiente virtual InterAge: um exemplo voltado para introdução da FMC no Ensino Médio. Física na Escola, São Paulo, v. 5, n. 2, p. 15-9, 2004.

SACRISTÁN, J. G. O currículo: uma reflexão sobre a prática. Trad. Ernani F. da F. Rosa. 3. ed. Porto Alegre: ArtMed, 2000.

SAVERY, J. R.; DUFFY, T. M. Problem Based Learning: an instructional model and its constructivist framework. Educacional Technology, Indiana University, v. 35, p. 31-8, 1995.

SCHÖN, D. A. Formar professores como profissionais reflexivos. In: NÓVOA, A. (Org.). Os professores e sua formação. Lisboa: Dom Quixote, 1992. p. 77-92.

STRUCHINER, M. et al. Elementos fundamentais para o desenvolvimento de ambientes construtivistas de aprendizagem a distância. Tecnologia Educacional, Rio de Janeiro, v. 26, n. 142, p. 3-11, 1998.

Artigo recebido em setembro de 2007 e aprovado em maio de 2008. 